\title{
Article
}

\section{Inner Structure and Mechanical Properties of Recycled Polypropylene}

\author{
Shigeru YaO, Aya Tominaga, Youhei FuJIKawa, Hiroshi SeKIGUCHI, and Eiichi TAKatori* \\ Department of Chemical Engineering, Fukuoka University \\ "TOSOH A\&R Center Co. Ltd. \\ (Received : November 12, 2012)
}

\begin{abstract}
We investigated the molecular characteristics of virgin polypropylene and recycled polypropylene that was obtained from byproducts (for example, runners, etc.) at the injection-molding of virgin polypropylene. We also tested the tensile properties of $3 \mathrm{~mm}$-thick specimens made from each sample. The results showed that the two materials had almost the same molecular characteristics and tensile properties. However, their fractured surfaces were very different. Furthermore, a $100 \mu \mathrm{m}$-thick film of the recycled sample was very brittle compared to a film made from the virgin polypropylene. The recycled sample had a history of shear deformation at the time of injection-molding, and may have a unique inner structure due to shear deformation. We found a unique peak in an endothermic curve with a rapid heating rate, and this result supports the above assumption. We also found that the dependence of the tensile fracture energy on the duration of UV irradiation was essentially the same in these samples. Based on these results, we propose a new theoretical equation that can estimate the fracture ratio of molecules.
\end{abstract}

Key Words: Recycle plastic / Tensile fracture energy / Shear induced crystallization / Tie molecule / Inner structure

\section{INTRODUCTION}

To address the dual problems of the depletion of natural resources and the environmental impact of a growing volume waste, effective recycling of various products and materials has become an important challenge. Especially, the amount of plastic waste is extremely large, and thus it is important to establish effective methods for recycling these materials rapidly. ${ }^{1,2)}$

There are essentially three ways to recycle plastics. ${ }^{3)}$ In the thermal recycling, plastics are incinerated to produce heat. In the chemical recycling, the monomers or organic chemicals that are obtained from polymers are reused. Finally, in the material recycling, recycled plastics are used for molding as is.

Among these methods, thermal recycling requires the least amount of energy. However, from an environmental perspective, this method should be considered a last resort. Chemical recycling requires large amounts of energy and very complicated processes, and even then is not suitable for use with every macromolecular species. Therefore, ideally, material recycling should be repeated as many times as possible before the plastic is subjected to thermal recycling.

However, the mechanical properties of the products of material recycling are believed to be inferior to those of products molded from virgin plastics, and thus their application is presently limited. ${ }^{4)}$

Generally, these inferior mechanical properties are believed to be due to the degradation of plastics, but there have been few detailed investigations on this subject. ${ }^{5-8)}$ Especially, the physical properties of pre-consumer recycling plastic made from byproducts (for example, runners, etc.) during molding have not been investigated much. In this study, we compared the molecular and physical properties of virgin polypropylene (VPP) to those of pre-consumer recycling polypropylene (PreRPP). We also investigated the effects of UV light on the mechanical properties of these samples.

\section{EXPERIMENTS}

As the VPP sample, we used an injection-molding and transparent grade polypropylene (molecular weight, density and MFR are shown in Fig. 1 and Table I). The Pre-RPP samples were pelletized from the byproducts of injectionmolding of the VPP test pieces. No additives were used in these molding and pelletizing processes.

As an index of degradation, we compared the absorption strengths of carbonyl $\left(1733 \mathrm{~cm}^{-1}\right)$ and isopropyl groups $\left(1165 \mathrm{~cm}^{-1}\right)$ in each sample by FT-IR. The melting behaviors were measured by DSC.

For the measurement of mechanical properties, we 
investigated the tensile properties of $3 \mathrm{~mm}$-thick test pieces (JIS K7162) and $100 \mu$ m-thick films (JIS K 7113 $2(1 / 2)$ ). Table II shows the tensile test conditions. In these measurements, we tested five samples and evaluated their mean values and deviations.

We also evaluated the tensile fracture energy from the area under the stress-strain curve.

\section{RESULTS AND DISCUSSION}

Table I shows the densities and MFR of VPP and Pre-RPP. Figure 1 shows the results of gel permeation chromatography (GPC), as well as both the number and weight averaged molecular weights based on a polystyrene standard and the ratio of $M_{w} / M_{n}$ (We converted the polystyrene equivalent molecular weight to real molecular weight). ${ }^{9)}$ As shown in the figure, Pre-RPP had a slightly higher proportion of low molecular weight components. Consistent with the results of GPC, Pre-RPP also has a slightly higher MFR value. On the other hand, Pre-RPP is more dense than VPP, which indicates that the crystallinity of Pre-RPP is larger than that of VPP.

However, these differences are almost negligibly small and we can conclude that these samples have almost the same molecular properties. Therefore, we can also conclude that a history of injection-molding had little, if any, effect on the molecular properties.

In Table I we also show the results of FT-IR for both VPP and Pre-RPP. In this measurement, we used transmission mode for a $100 \mu \mathrm{m}$-thick sample. The vertical axis shows the ratio of the absorption strengths of carbonyl $\left(1733 \mathrm{~cm}^{-1}\right)$

Table I. Density, MFR and Index of degradation of virgin and recycled samples.

\begin{tabular}{|c|c|c|c|}
\hline Sample & $\begin{array}{c}\text { Density } \\
(\mathrm{kg} / \mathrm{m} 3)\end{array}$ & $\begin{array}{c}\text { MFR } \\
(\mathrm{g} / 10 \mathrm{~min})\end{array}$ & Degradation Index*1 \\
\hline VPP & 900 & 31.9 & $0.00911( \pm 0.00114) * 2$ \\
\hline Pre-RPP & 904 & 43.0 & $0.00933( \pm 0.00381) * 2$ \\
\hline
\end{tabular}

*1 Absorption strengths ratio between carbonyl group $\left(1733 \mathrm{~cm}^{-1}\right)$ and isopropyl group $\left(1165 \mathrm{~cm}^{-1}\right)$ *2 Number in brackets represents the standard deviation.

Table II. Tensile test conditions

\begin{tabular}{|c|c|c|}
\hline Sample thickness & $3 \mathrm{~mm}$ test piece & $100 \mu \mathrm{m}$ film \\
\hline Temperature & \multicolumn{2}{|c|}{$23^{\circ} \mathrm{C}$} \\
\hline Humidity & \multicolumn{2}{|c|}{$50 \% \mathrm{RH}$} \\
\hline Elongation speed & $50 \mathrm{~mm} / \mathrm{min}$ & $5 \mathrm{~mm} / \mathrm{min}$ \\
\hline Chuck distance & $115 \mathrm{~mm}$ & $40 \mathrm{~mm}$ \\
\hline
\end{tabular}

and isopropyl groups $\left(1165 \mathrm{~cm}^{-1}\right)$ in each sample. We used this ratio as an index of degradation. The variation in the value measured for Pre-PP was slightly greater than that for VPP, although the ratios themselves were almost the same. Thus, polypropylene does not degrade much at the injectionmolding. ${ }^{9}$

Figure 2 shows the stress-strain curves for a $3 \mathrm{~mm}$-thick test piece for VPP and Pre-PP (injection-molded according to JIS K7162 1B and the conditions of injection-molding are same). Consistent with the results shown in Figs. 1 and Table II, the stress-strain profiles of the two samples are almost the same. This result suggests that a useful injection-molded product can be made from Pre-RPP if it is sufficiently thick (above $3 \mathrm{~mm}$ or so).

Figure 3 shows SEM images of the cross-sections of $3 \mathrm{~mm}$ thick test samples broken in liquid nitrogen. The cross-section of the VPP specimen shows a smooth surface, while that of the Pre-RPP specimen shows a rough surface. This indicates that the inner structures (including the crystalline structures) of VPP and Pre-RPP are quite different from each other.

Figure 4 shows the stress-strain curves for $100 \mu \mathrm{m}$-thick films (the films are punched out from a pressed film shaped according to JIS K7113 2(1/2)). As shown in Fig. 4(a), the VPP film extends very much. In contrast, the Pre-PP film breaks as soon as it reaches a yield value [Fig. 4(b)]. These results are significantly different from those in Fig. 2. The tensile fracture energy of Pre-RPP as calculated from the area under the of stress-strain curve is nearly two orders of magnitude smaller than that of VPP, which explains why the former is so brittle.

It is well known that shear-induced crystallization occurs when molten polymers are subjected to shear deformation during processing and the resulting inner structure influences the mechanical properties of the product. According to Kanaya

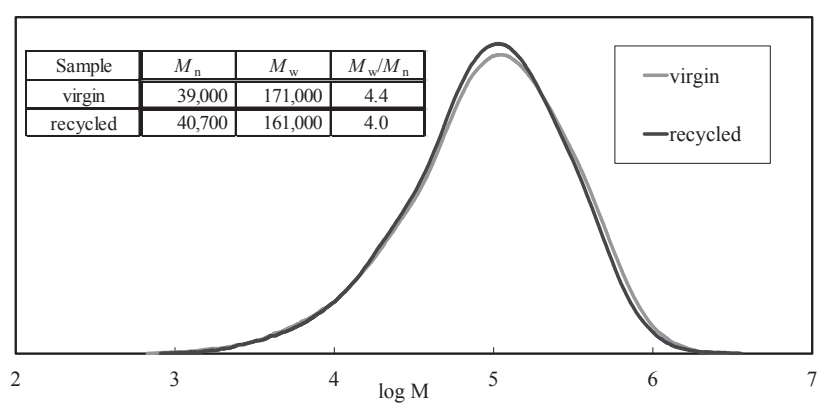

Fig. 1. GPC results for virgin and recycled polypropylene. The table shows the number averaged and weight averaged molecular weight and polydispersity of each sample. 
and co-workers, shear-induced crystallization begins to occur with a shear rate of at least $3 \mathrm{sec}^{-1} \cdot{ }^{10-12)}$ It has also been shown that the inner structures caused by shear deformation are very stable at high temperature. ${ }^{13,14)}$ The Pre-RPP used in this study was pelletized from the byproducts of injection-molding, and thus had been subjected to high shear deformation and is thought to have shear-induced inner structures. Our present results suggest that the temperature and duration of Pre-PP pelletization in this study were relatively low and short, so that the inner structures were remained.

Our results also suggest that the inner structures of VPP and Pre-RPP are quite different. The results in Figs. 3 and 4 indicate that both the crystal and amorphous structures (including tie molecules between crystal lamella) are very different, and this could explain the low tensile properties of Pre-RPP.
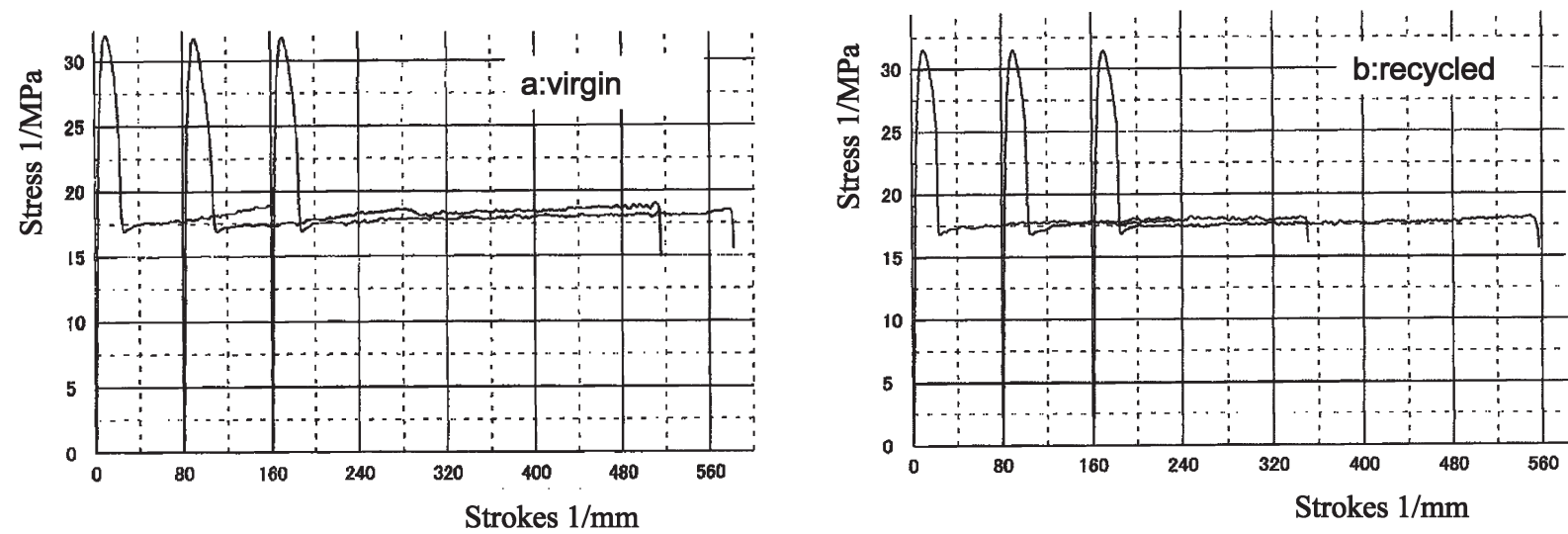

Fig. 2. Stress-strain curves for $3 \mathrm{~mm}$-thick test pieces of virgin and recycled samples.
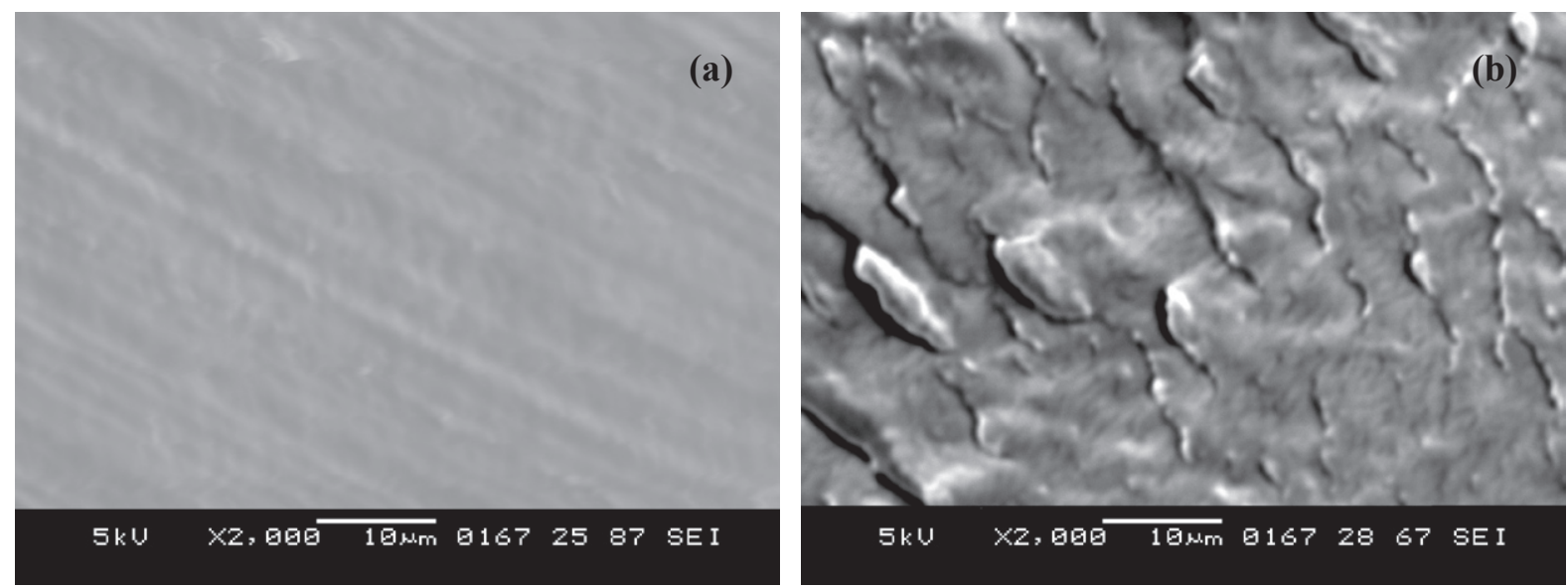

Fig. 3. SEM images of fractured surfaces of test pieces (3 mm-thick) molded from (a) virgin and (b) recycled pellets.
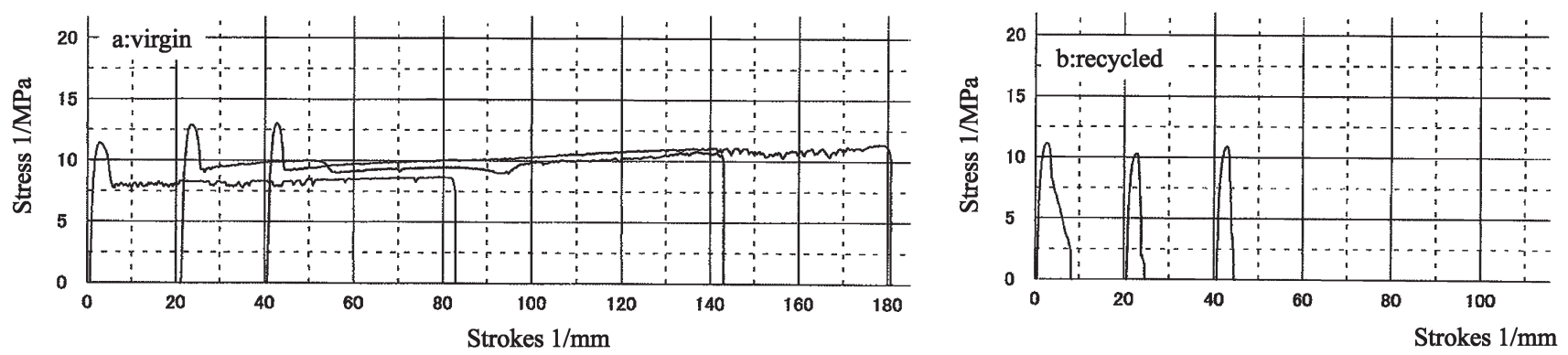

Fig. 4. Stress-strain curves of $100 \mathrm{~mm}$-thick films of virgin and recycled samples. 
Figure 5 shows the melting behaviors of the VPP and Pre-RPP samples at different heating rates $\left(5^{\circ} \mathrm{C} / \mathrm{min}\right.$ and $50{ }^{\circ} \mathrm{C} / \mathrm{min}$ ). In this time the amounts of the each sample were about $7 \mathrm{mg}$. Before the measurements, samples were heated to $210{ }^{\circ} \mathrm{C}$ (heating rate was $20{ }^{\circ} \mathrm{C} / \mathrm{min}$ ), hold $2 \mathrm{~min}$ at this temperature and cooled at room temperature. As shown in Fig. 5(a), when the heating rate was slow, although the endothermic curve of Pre-RPP was slightly disturbed, the melting behaviors were almost the same. On the other hand, when the heating rate was $50{ }^{\circ} \mathrm{C} / \mathrm{min}$ [Fig. 5(b)], while the peak of melting temperatures of the two samples were almost the same, the shapes of the endothermic curves were slightly different; the curve for Pre-RPP shows a small shoulder.

It is well known that the recycled plastics easily degrade. To make sure that this is also same for the pre-consumer recycling plastic, in this study, we compared the durability of VPP and Pre-PP by UV irradiation. Figure 6 shows the dependence of tensile fracture energy on the duration of UV irradiation for $100 \mu \mathrm{m}$-thick films of both VPP and Pre-RPP. As shown, the value for VPP is about 50 times greater than that for Pre-RPP, while the slopes of the curves are very similar.

In Figure 7, we shifted the results for VPP to the left and superimposed them on the results for Pre-RPP. As shown, the superposition had been very successful and there was a close relation between the two trends.

According to previous investigations, the axial elastic modulus of a semi-crystalline polymer mainly depends on the number of taut tie molecules present. ${ }^{15,16)}$ Other researchers have suggested that the fracture energy is proportional to the number of chains that cross a unit fracture surface. ${ }^{17,18)}$ These investigations suggest that the polymer fracture energy depends on the number of molecules that sustain adhesion between domains (referred to here as sustaining molecules).

If we assume that the energy for fracture depends uniquely on the number of sustaining molecules between domains, we obtain equation (1).

$$
E_{B}(t)=E_{B 0} \cdot N(t)
$$

Where $E_{B}(t)$ is the tensile fracture energy at time $t, N(t)$ is the number of sustaining molecules at $t$, and $E_{B 0}$ is a constant.
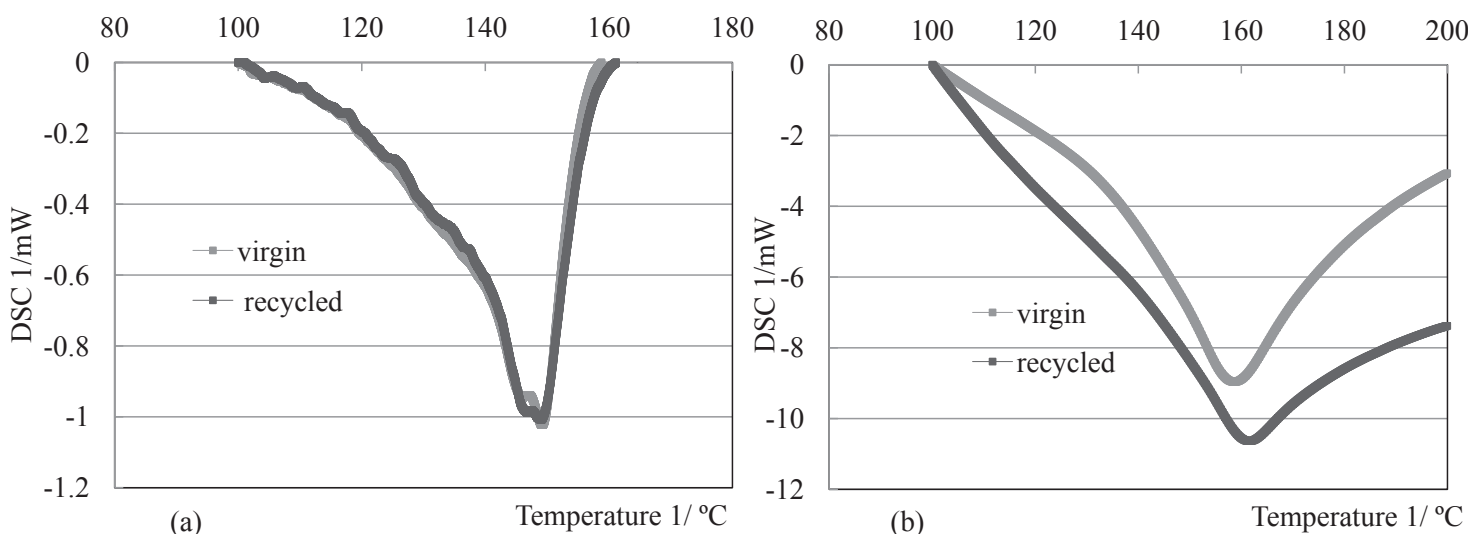

Fig. 5. DSC endothermic curves of virgin and recycled samples. (a) : heating rate is $5^{\circ} \mathrm{C} / \mathrm{min}$, and (b): heating rate is $50{ }^{\circ} \mathrm{C} / \mathrm{min}$. (in case (b) we did not correct the base slope.)

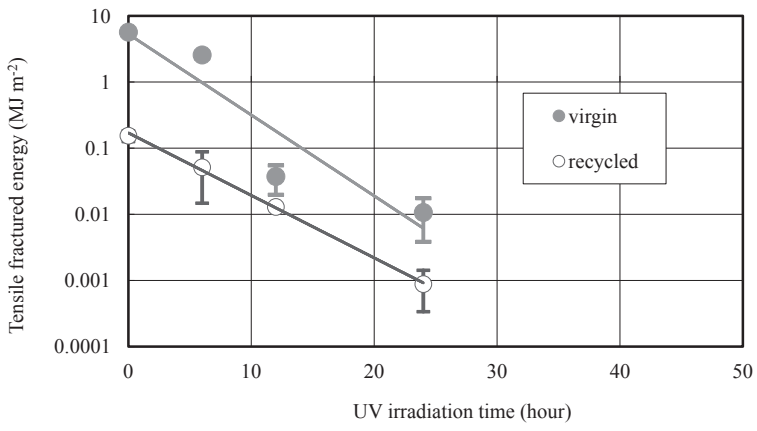

Fig. 6. Dependence of the tensile fracture energy of virgin and recycled samples on the duration of UV irradiation.

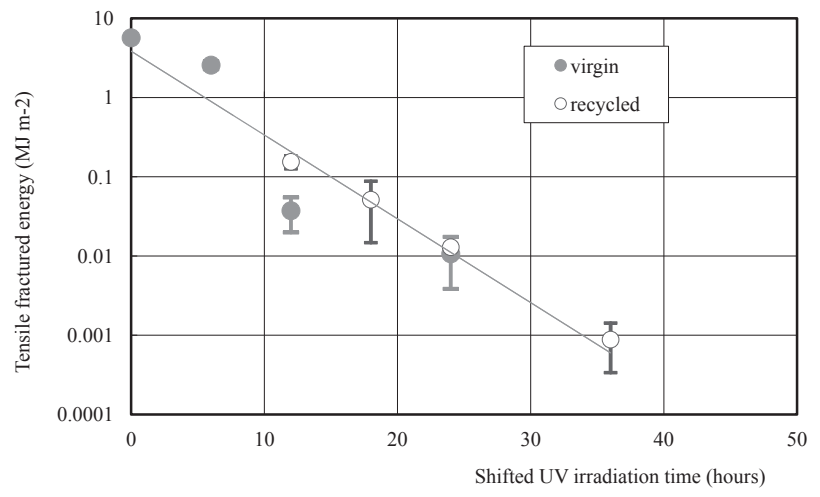

Fig. 7. Superimposed result in Fig. 8 . 
We can consider that UV irradiation may break some of the polymer chains, and a chain that has broken once could break again in the same manner.

While all of the broken molecular chains will be sustaining molecules when they break for the first time, over time, these broken non-sustaining molecules can break again. Thus, the number of sustaining molecules after time $t$ has passed can be given by equation (2).

$$
\begin{aligned}
N(t) & =N(t-1)-\frac{N(t-1)}{N_{0}} \cdot a=\frac{N_{0}-a}{N_{0}} \cdot N(t-1) \\
& =\left(\frac{N_{0}-a}{N_{0}}\right)^{2} \cdot N(t-2)=\cdots \\
& =N_{0}\left(\frac{N_{0}-a}{N_{0}}\right)^{t}=N_{0} \cdot(1-p)^{t}
\end{aligned}
$$

Where $N_{0}$ is the initial number of sustaining molecules, $a$ is the number of broken molecules per unit time, $t$ is time, and $p$ is the probability of breakage.

Therefore, the probability that molecules that are directly related to the tensile fracture energy will decrease over time, and the time-dependence of the tensile fracture energy can be represented by equation (3).

$$
E_{B}(t)=E_{B 0} \cdot N(t)=E_{B 0} \cdot N_{0}\left(\frac{N_{0}-a}{N_{0}}\right)^{t}=E_{B 0} N_{0}(1-p)^{t}
$$

The time-dependence of the tensile fracture energy from Fig. 7 gives equation (4).

$$
E_{B}(t)=3.85 \cdot e^{-0.244 t}
$$

By comparing eqs. (3) and (4), we can derive the probability $p$. In this investigation, $p=0.22$. According to this result, under UV irradiation, about $20 \%$ of all molecules break per unit time (one hour), and this probability is the same for VPP and Pre-RPP samples.

The difference in the tensile fracture energy between the VPP and Pre-RPP samples is due to the difference in the initial number of sustaining molecules. Based on Fig. 7, the results for Pre-RPP are offset from those for VPP by about 12 hours. Thus, according to eq.(3), the initial number of sustaining molecules in Pre-RPP is about $5 \%$ of that in VPP.

\section{CONCLUSION}

In this study, we investigated the molecular characteristics and mechanical properties of virgin polypropylene (VPP) and recycled polypropylene that was obtained from byproducts (runners, etc.) at the time of injection-molding (pre-consumer recycling plastic: Pre-RPP). We found that the molecular weight, polydispersity, and degree of degradation of the two samples were almost the same. Consistent with these results, the tensile strengths of $3 \mathrm{~mm}$-thick test pieces of VPP and PreRPP were about the same. However, fractured cross-sections of these samples were very different (VPP: smooth, Pre-RPP: rough) and the tensile strengths of $100 \mu \mathrm{m}$-thick films were also very different (VPP: ductile, Pre-RPP: brittle). The results of DSC measurements under a high heating rate suggest that these differences are due to the difference between their inner structures, and that of Pre-RPP might to be influenced by shear deformation in the process of injection-molding. From the results regarding the dependence of the tensile fracture energy on the duration of UV irradiation, we constructed a theoretical equation that can estimate the fracture rate of sustaining molecules. This equation shows that the initial number of sustaining molecules in Pre-RPP is about $5 \%$ of that in VPP.

The results of this investigation suggest that Pre-RPP exhibits poor mechanical characteristics and durability due to its inner structure. Thus, if we could modify the inner structure and the number of sustaining molecules of Pre-RPP by treatment with heat or solvent, we might be able to improve its mechanical properties and durability.

\section{REFERENCES}

1) Yamasue E, Minamino R, Daigo I, Okumura H, Ishihara NK, J Japan Inst Metals, 74, 811 (2010).

2) Report of Special Research from the National Institute for Environmental Studies, Japan, National Institute for Environmental Studies, (2006).

3) Al-Salem SM, Lettieri P, Baeyens J, Waste Manage, 29, 2625 (2009).

4) Nishiyama Y, Nippon Gomu Kyokaishi, 81, 388 (2008).

5) Miyagawa E, Tokumitsu K, Tanaka A, Nitta K, Polym Degrad Stabil, 92, 1948 (2007).

6) Valenza A, Mantia FPL, Polym Degrad Stabil, 19, 135 (1987).

7) Valenza A, Mantia FPL, Polym Degrad Stabil, 20, 135 (1988).

8) Gonzalez VAG, Velazquez GN, Sanchez JOA, Polym Degrad Stabil, 60, 33 (1998).

9) Mori S, Barth HG, "Size Exclusion Chromatography", Springer, Berlin (1999), p106-107

10) Ogino $Y$, Fukushima H, Matsuba G, Takahashi N, Nishida $K$, Kanaya T, Polymer, 47, 5669 (2006).

11) Ogino Y, Fukushima H, Takahashi N, Matsuba G, Nishida K, Kanaya T, Macromolecules, 39, 7617 (2006).

12) Hayashi $Y$, Matsuba G, Zhao Y, Nishida K, Kanaya T, Polymer, 50, 2095 (2009). 
13) Elmoumni A, Winter HH, Waddon AJ, Friutwala H, Macromolecules, 36, 6453 (2003).

14) Cavallo D, Azzurri F, Balzano L, Fuuari SS, Alfonso GC, Macromoleciles, 43, 9394 (2010).

15) Peterlin A, Int J Fract, 11, 761 (1975).
16) Soare JBP, Abbott RF, Kim JD, J Polym Sci, B, Polym Physics, 38, 1267 (2000).

17) Prager S, Tirrell M, J Chem Phys, 75, 5194 (1981).

18) Mikos AG, Peppas NA, J Chem Phys, 88, 1337 (1988). 